Note: This is a draft of a paper being submitted for publication. Contents of this paper should not be quoted nor referred to without permission of the author(s).

To be submitted to 1999 Spring Materials Research Society Meeting.

Symposium Y - Wide-Band Gap Semiconductors for High-Power,

High-Frequency, and High-Temperature Applications

Editors - S. Binari, A. Burk, M. Melloch, and C. Nguyen.

\title{
The Effects of Damage on Hydrogen-Implant-Induced Thin-Film Separation from Bulk Silicon Carbide
}

R. B. Gregory, T. A. Wetteroth, and S. R. Wilson Motorola Inc, Tempe, AZ

O. W. Holland and D. K. Thomas

Oak Ridge National Laboratory, Oak Ridge, TN

\begin{abstract}
"The submitted manuscript has been authored by a contractor of the U.S. Government under contract No. DE-AC05-960R22464.

Aecordingly, the U.S. Gowernment retains a nonexclusive, royalty-free license to publish or

norfeluse, ro

reproduce the poblished form of this

contribution, or allow others to do so, for U.S.
Government purposes."
\end{abstract}

Prepared by the

Oak Ridge National Laboratory

Oak Ridge, Tennessee 37831

managed by

LOCKHEED MARTIN ENERGY RESEARRCH CORP.

for the

U.S. DEPARTMENT OF ENERGY

under contract DE-AC05-960R22464

August 1999 


\title{
THE EFFECTS OF DAMAGE ON HYDROGEN-IMPLANT-INDUCED THIN-FILM SEPARATION FROM BULK SILICON CARBIDE
}

\author{
R.B. GREGORY * O.W. HOLLAND **, D.K. THOMAS **. T.A. WETTEROTH * \\ S.R. WILSON * \\ *Motorola Inc., Semiconductor Products Sector, Tempe. Arizona \\ **Oak Ridge National Laboratory, Solid State Division. Oak Ridge. TN. 3783 1-6048
}

\section{ABSTRACT}

Exfoliation of $\mathrm{SiC}$ by hydrogen implantation and subsequent annealing forms the basis for a thin-film separation process which, when combined with hydrophilic wafer bonding. can be exploited to produce silicon-carbide-on-insulator, SiCOI. SiC thin films produced by this process exhibit unacceptably high resistivity because defects generated by the implant neutralize electrical carriers. Separation occurs because of chemical interaction of hydrogen with dangling bonds within microvoids created by the implant, and physical stresses due to gas-pressure effects during post-implant anneal. Experimental results show that exfoliation of $\mathrm{SiC}$ is dependent upon the concentration of implanted hydrogen, but the damage generated by the implant approaches a point when exfoliation is, in fact, retarded. This is attributed to excessive damage at the projected range of the implant which inhibits physical processes of implantinduced cleaving. Damage is controlled independently of hydrogen dosage by elevating the temperature of the $\mathrm{SiC}$ during implant in order to promote dynamic annealing. The resulting decrease in damage is thought to promote growth of micro-cracks which form a continuous cleave. Channeled $\mathrm{H}^{+}$implantation enhances the cleaving process while simultaneously minimizing residual damage within the separated film. It is shown that high-temperature irradiation and channeling each reduces the hydrogen fluence required to affect separation of a thin film and results in a lower concentration of defects. This increases the potential for producing SiCOI which is sufficiently free of defects and, thus, more easily electrically activated.

\section{INTRODUCTION}

Hydrogen implantation through an oxide film followed by hydrophilic wafer bonding and a thermal cycle is a process developed to cleave a thin film of silicon-on-insulator (SOI). ${ }^{2}$ The process has recently been applied to produce silicon carbide-on-insulator (SiCOI) films for possible use as a wide bandgap semiconductor in power $\mathrm{rf}$ and switching devices. ${ }^{2}$

$\mathrm{SiC}$ thin films separated from bulk material using this process have measured too resistive, a condition attributed to damage in the $\mathrm{SiC}$ thin film caused by the hydrogen implant itself. The experiments described in this work are motivated by the desire to understand the implant damage mechanisms in order to make the separation process more efficient and produce defect-free, lowresistivity $\mathrm{SiC}$.

The problem is illustrated in Figure 1 which shows a schematic of the hydrogen-implantinduced separation process and a channeled RBS spectrum of SiCOI $(-500 \mathrm{~nm})$ produced by this process. Backscattered counts from $\mathrm{Si}$ in the SiCOI (integrated over channets 540-640) measure 824 greater than similarly measured counts from virgin $\mathrm{SiC}$. Calculating density using the RBS data, one measures $1.27 \times 10^{20}$ displaced atoms $/ \mathrm{cm}^{3}$. These vacancies have the potential to cause 


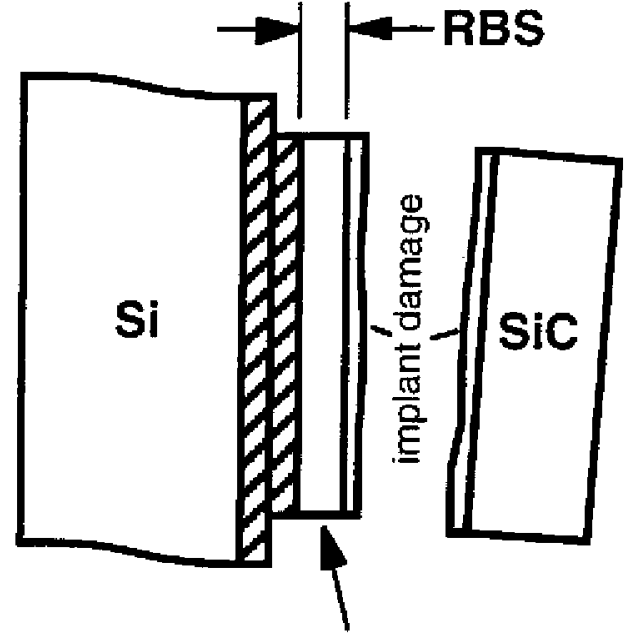

Bonded and cleaved SiC

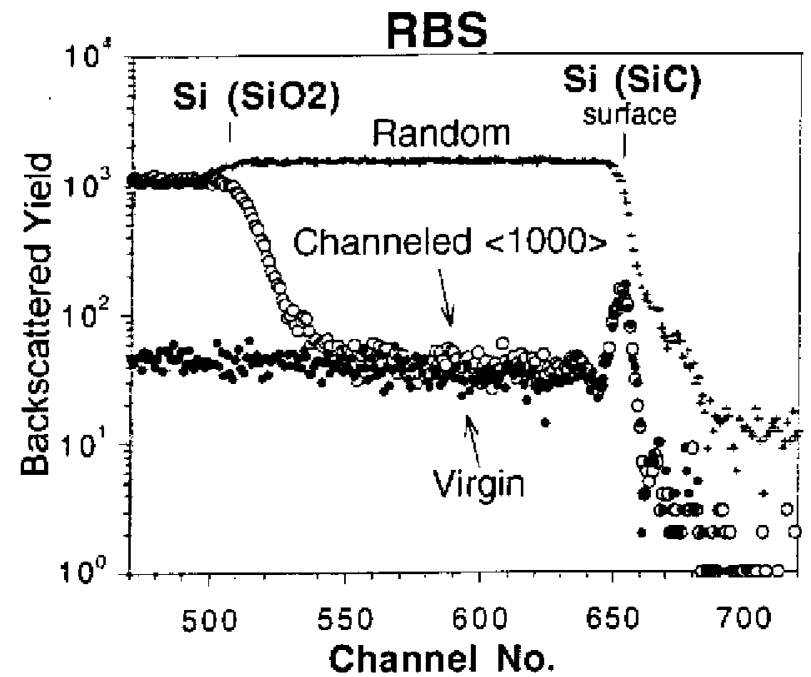

Figure 1. Schematic diagram of transferred and cleaved SiC (left) and RBS-channeling spectra of the transferred $\mathrm{SiC}$ film (right) ... $\mathrm{H}^{+}$implant damage polished off before analysis.

the deactivation of electrical carriers in material with typical doping concentrations of $10^{17}-10^{18}$ atoms $/ \mathrm{cm}^{3}$.

Previous work (with $\mathrm{Si}$ ) shows that the process to cleave a thin film by hydrogen implantation followed by a thermal cycle is a combination of hydrogen chemistry and physical processes. The implant results in the formation of platelet-like microvoids which, during subsequent anneal, expand dure to gas pressure of excess lydrogen. This links the microvoids into a continuous fracture, cleaving a thin film from the bulk wafer. ${ }^{3}$ The use of $\mathrm{H}^{+}$-implantation to affect transfer of a thin film from a bulk Si wafer was based upon observations of bubbling and exfoliation of implanted Si wafers after annealing. 4.5

The effects of ion-induced damage on the efficiency of the transfer process and its dependence on $\mathrm{H}^{+}$dose are demonstrated by observing exfoliation of $\mathrm{SiC}$ following $\mathrm{H}^{+}$implantation and anneal. Means to control damage independently of $\mathrm{H}$ dose are demonstrated with elevated-temperature and channeled implantation. It is proposed that channeled implantation generates less residual damage from the surface to at least half the projected range. $1 / 2 \mathrm{R}_{\mathrm{p}}$, of the implant simply because crystalline axes of $\mathrm{SiC}$ are aligned with the $\mathrm{H}^{+}$beam. decreasing the cross section for ion-solid collisions. The elevated temperature implants affect insitu. dynamic annealing in order to control $\mathrm{H}^{+}$implant damage in $\mathrm{SiC}$.

\section{EXPERIMENTS and RESULTS}

\section{Random vs. Channeled $\mathrm{H}^{+}$-implantation}

Experiments to measure damage and exfoliation of $\mathrm{SiC}$ as a function of $\mathrm{H}$ dose were accomplished using bulk $\mathrm{SiC}$ samples, $4 \mathrm{H}$ polytype, supplied as research grade material by Cree Research. They were implanted with $60 \mathrm{keV} \mathrm{H}^{+}$to doses ranging from $2.5 \times 10^{16}$ to $10.5 \times 10^{16}$ atoms $/ \mathrm{cm}^{2}$. Samples were tilted $7^{\circ}$ from normal to affect random beam alignment. Additional samples were implanted with the $\mathrm{H}^{+}$beam aligned to [1000] axes to affect channeled implants over the same dose range. Damage analyses were accomplished by Rutherford backscattering (RBS)-channeling using a $2.3 \mathrm{He}^{i+}$ ion beam aligned with [1000] axes normal to the surface of the 
sample. Bachscattered inns were detected at $160^{\circ}$ relative to the inciden beam using a solid state. surface barrier detector. Samples were then annealed in order to cause exfoliation of thin $\mathrm{SiC}$ from the bulk material. The anount of exfoliation was evaluated using optical microscops.

Figure 2 shows RBS-chameled spectra for three of the samples from the set generated to evaluate the effects of implant damage on exfoliation for random-implanted $H^{*}$. The spectra represent as-implanted samples at room - or ambient - temperature (RT). These spectra show that damage to the $\mathrm{SiC}$ at the projected range. $\mathrm{R}_{\mathrm{p}}$. increases with the $\mathrm{H}^{-}$implant dose. The scattering yields near $l / 2 R_{p}$ are also progressively greater (as a function of dose) than the yeld from the virgin reference sample indicating the presence of ion-induced. residual damage at this location in all the samples. This is possibly due to displaced atoms that either dechamel or directly backscatter the incident $\mathrm{He}^{-+}$ions. Analysis by positron annihilation spectroscopy (not shown) indicates the presence of open volume defects. the result of displaced atoms at concentrations below the sensitivity of RBS. Such defectivity mas be responsible for deactivating intrinsic carriers in $\mathrm{SiC}$ as previously reported for similarly implanted material."

Following RBS characterization. all samples were subjected to $950^{\circ} \mathrm{C}$. 15-minute anneals. then optically imaged using a microscope with Nomarski contrast. Figure 3 shows a portion of a series of optical micrographs produced to observe exfoliation of $\mathrm{SiC}$ as a function of dose for 60 $\mathrm{keV} \mathrm{H}{ }^{+}$implants done at RT. During the $950^{\circ} \mathrm{C}$. 15-minute anneal. bubble formation occurs as the $\mathrm{H}^{+}$dose approaches $4.5 \times 10^{16} / \mathrm{cm}^{2}$, as seell in the optical nicrograph [Figure 3(a)]. (Samples implanted with small increments of dose between $2.5 \times 10^{16}$ and $4.5 \times 10^{16} / \mathrm{cnt}^{2}$ revealed that the critical dose to produce exfoliation is very near $4.5 \times 10^{16} / \mathrm{cm}^{2}$.) Evidence for material removal or exfoliation of the $4.5 \times 10^{16} / \mathrm{cm}^{2}$ sample is clearly seen in Figure 3(a) by the appearance of broken bubbles. The amount of exfoliated surface material maximizes near a dose of $5.5 \times 10^{16} / \mathrm{cm}^{2}$

[Figure 3(b)], but at higher doses exfoliation decreases as seen in Figures 3(c) and (d). indicating a retrograde effect of the $60 \mathrm{keV} \mathrm{H}^{+}$implant to doses greater than $5.5 \times 10^{16} / \mathrm{cm}^{2}$.

The information conveyed by the images in Figure 3 is represented graphically in Figure 4 which shows the percentage of area that exfoliates following the $950^{\circ} \mathrm{C}$ anneal. Two sets of data are graphed. one for the randomly implanted samples and one for channel-implanted samples. One sees that channeled implants shift the onset of exfoliation (as well as maximum exfoliation) to approximately $1 \times 10^{16}$ lower dose than the random implants. Furthermore, the maximum

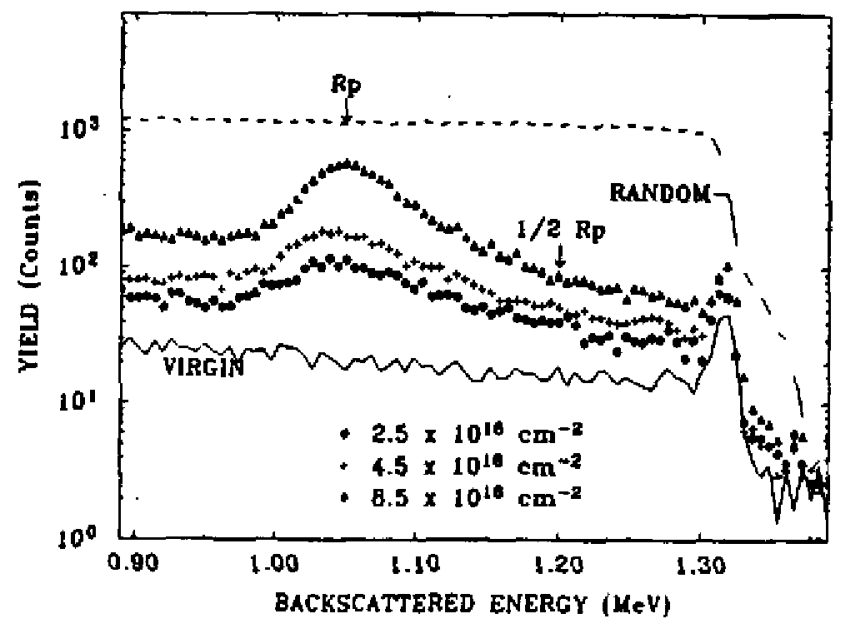

Figure 2. RBS-channeled spectra for $\mathrm{Si}$ in $60 \mathrm{keV} \mathrm{H} \mathrm{H}^{+}$-implanted $\mathrm{SiC}$. Three dosages shown are $4.5 \times 10^{16} .6 .5 \times 10^{16}$. and 10.5 $\times 10^{16} / \mathrm{cm}^{2}$. Relerence spectra include the aligned yiejd from nonimplanted (virgin) $\mathrm{SiC}$ and the randomized yield from an implanted sample. 


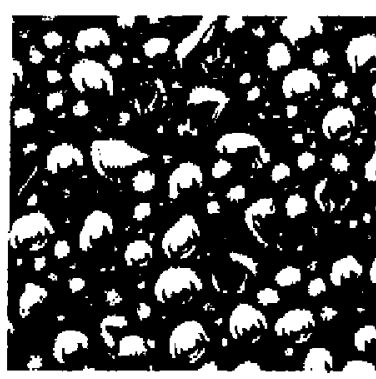

(a)

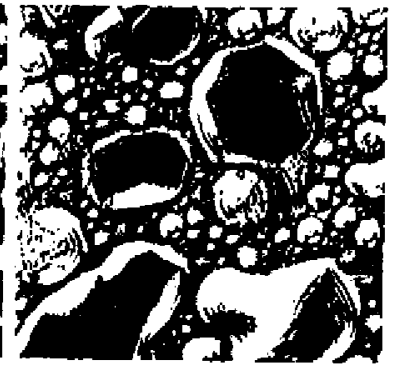

(b)

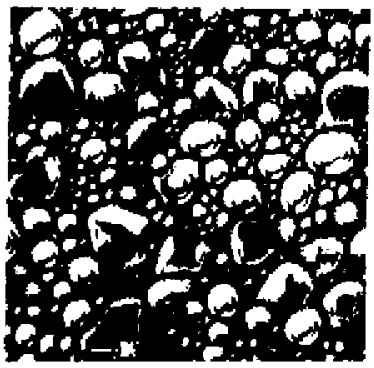

(c)

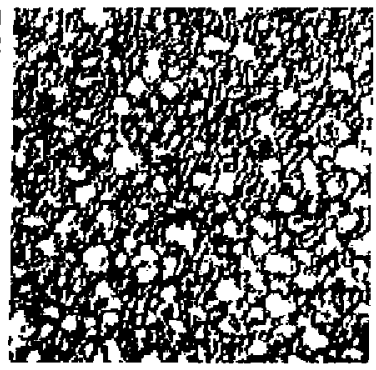

(d) $100 \mu \mathrm{m}$

Figure 3. Nomarski optical micrographs of SiC implanted with $60 \mathrm{keV} \mathrm{H}^{+}$to dose (a) $4.5 \times 10^{16}$, (b) $5.5 \times 10^{16}$, (c) $6.5 \times 10^{16}$, and (d) $8.5 \times 10^{16} / \mathrm{cm}^{2}$, after furnace annealing at $950^{\circ} \mathrm{C}$ for 15 minutes.

exfoliated area increases from $37 \%$ for the random implant (dosed $5.5 \times 10^{16} / \mathrm{cm}^{2}$ ) to $69 \%$ for the channeled implant (dosed $4.5 \times 10^{16} / \mathrm{cm}^{2}$ ). The rate of retrograde behavior of exfoliation appears the same for both random and channeled series.

SIMS depth profiles of hydrogen in random and channel-implanted samples are shown in Figure 5. Each of the samples was implanted with $60 \mathrm{keV} \mathrm{H}^{+}$to $2.0 \times 10^{16} / \mathrm{cm}^{2}$, then annealed. The dose was held low enough to prevent exfoliation of the $\mathrm{SiC}$ during the anneal. The profiles show that the channeled implant has slightly greater range than the random implant. More significant, though, the retained hydrogen concentration measures almost three times greater for the channel-implanted sample.
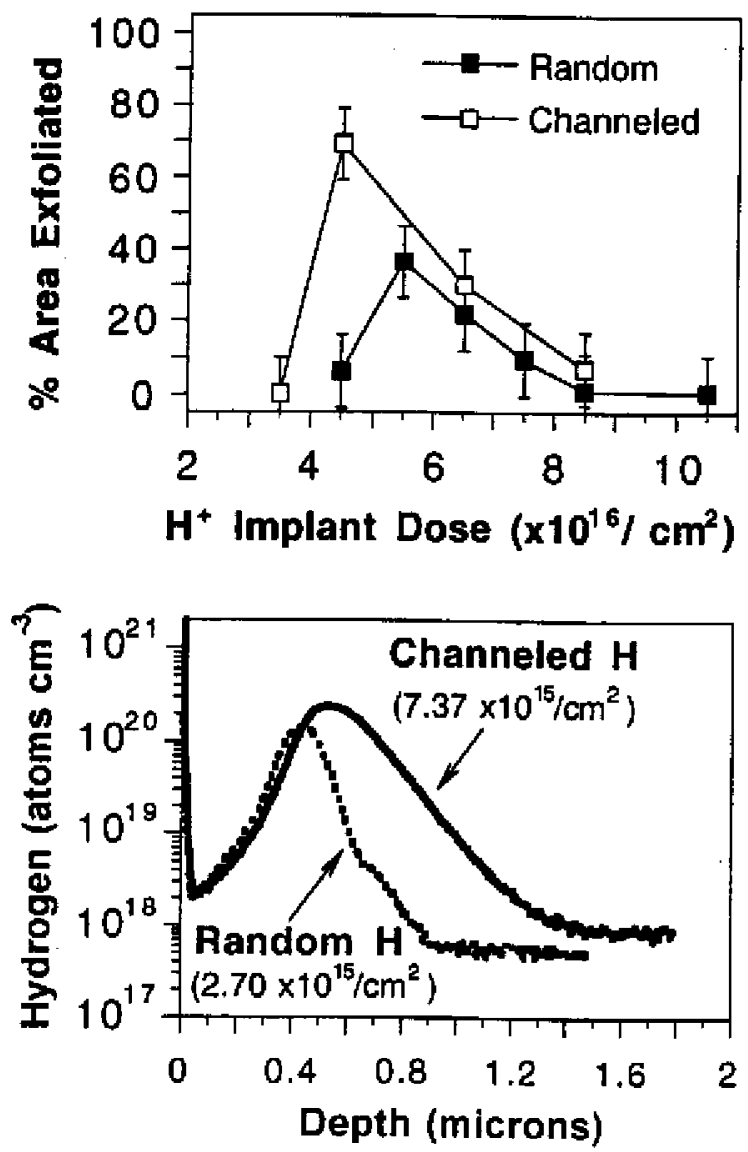

Figure 4. Percentage of area of exfoliated $\mathrm{SiC}$ as a function of $60 \mathrm{keV} \mathrm{H}$ implant dose. Two sample series graphed, one which was implanted in a random direction and one implanted with samples aligned to [1000] axes.
Figure 5. SIMS profiles of $60 \mathrm{keV}$ implanted hydrogen, dose $=2 \times 10^{16} / \mathrm{cm}^{2}$, following anneal at $950^{\circ} \mathrm{C}$ for 15 minutes. 


\section{Elevated Temperuture Implantation}

To learn the effects of elevated temperature implantation for controlling $\mathrm{H}^{+}$implant damige. two sets of $+\mathrm{H}-\mathrm{SiC}$ samples were implanted with $60 \mathrm{keV} \mathrm{H}$. One set was implanted at room temperature to doses ranging from $3.25 \times 10^{16}$ to $4.5 \times 10^{16} / \mathrm{cm}^{2}$. Samples of the second set $\mathrm{were}$ heated to $600^{\circ} \mathrm{C}$ during implant to doses ranging from $2.25 \times 10^{16}$ to $8.0 \times 10^{16} / \mathrm{cm}^{2}$.

Figure 6 shows RBS-channeling spectra for two samples $\mathrm{H}^{+}$-implanted to a dose of 2.0 $\times 10^{16} / \mathrm{cm}^{2}$. onc implanted at RT and the other with the temperature elevated to $600^{\circ} \mathrm{C}\left({ }^{-1}\right.$ hot" implant). It is clear from comparing the scattering yields in the respective samples that the hot implant generated less damage at $R_{p}$ as well as $1 / 2 R_{p}$. Also evident is a slightly greater $R_{p}$ for the hot implant. Optical micrographs for the series of hot implants (not shown) indicate the threshold dose for surface ex foliation of SiC during a $950^{\circ} \mathrm{C}$ anneal is $-2.75 \times 10^{16} / \mathrm{cm}^{2}$.

Optical micrographs shown in Figures 7(a) and (b) compare the surface morphology after annealing for hot and RT implants, respectively. The images show about the sanc degree of bubbling and exfoliation although the $\mathrm{H}^{+}$implant dose for the RT implant is much higher. 4.5 $\times 10^{16} / \mathrm{cm}^{2}$. compared with $2.75 \times 10^{16} / \mathrm{cm}^{2}$ for the $600^{\circ} \mathrm{C}$ implant. Previous work shows that the critical fluence for exfoliation decreases almost linearly with irradiation temperature. ${ }^{7}$

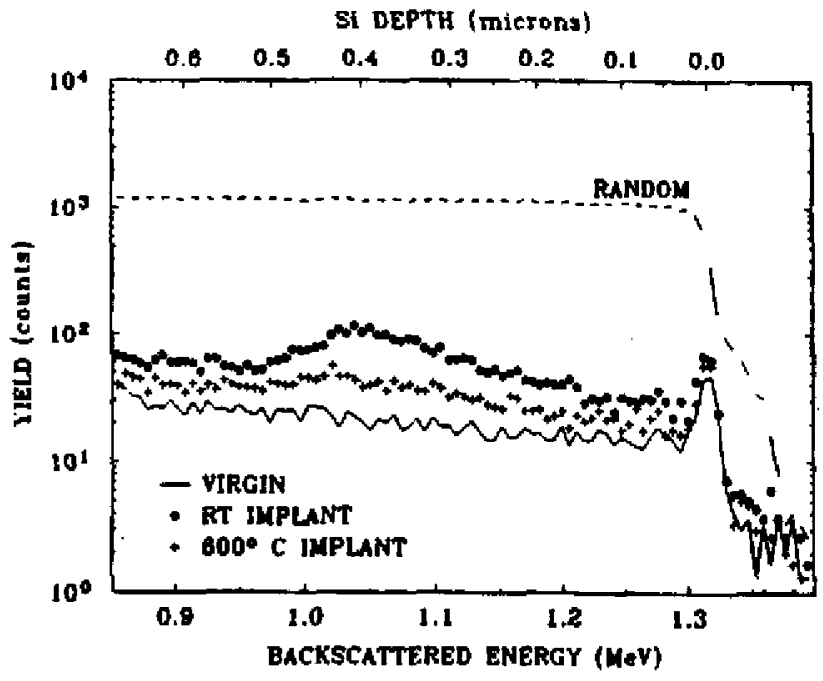

Figure 6. RBS-channeling spectra comparing damage to $\mathrm{SiC}$ following $60 \mathrm{keV} \mathrm{H}$. $2 \times 10^{16} / \mathrm{cm}^{2}$ implants at R.T. and $600^{\circ} \mathrm{C}$.

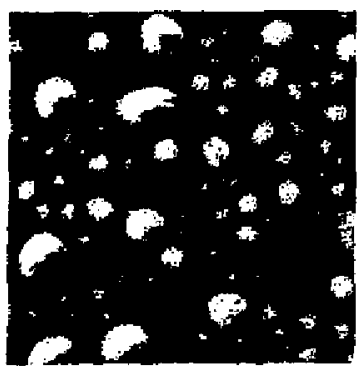

(a)

Figure 7. Nomarski optical micrographs of $60 \mathrm{keV} \mathrm{H}{ }^{+}$-implanted $\mathrm{SiC}$ showing similar degrees of bubbling and exfoliation for (a) $2.75 \times 10^{16} / \mathrm{cm}^{2}(9) 600^{\circ} \mathrm{C}$ and (b) $4.5 \times 10^{16} / \mathrm{cm}^{2} @ \mathrm{RT}$.

\section{DISCUSSION and CONCLUSIONS}

The dependence of surface exfoliation of $\mathrm{SiC}$ on $\mathrm{H}^{+}$dose and the retrograde behavior of exfoliation as damage increases beyond a specific dose supports the the following model. Both the hydrogen concentration and the lattice damage affect the degree of exfoliation. Both increase with implantation dose, but damage retards exfoliation. It is clear that more hydrogen available within the lattice will lead to more bubbling and exfoliation, but the role of damage in suppressing the effect is not obvious. As seen from previous work with $\mathrm{H}^{+}$-implanted $\mathrm{Si}$, the formation of extended defects (i.e... platelets) is critical to the formation of microcracks within the lattice. ${ }^{3}$ These microcracks and their ability to expand and interconnect yield the large macroscopic regions within the lattice which become separated from the underlying substrate either during 
exfoliation or thin-film transfer. One anticipates that substantial lattice damage may inhibit the formation of such macroscopic regions by hindering or stopping the propagation of the microcracks and thus preventing them from forming an interconnecting network.

The present work demonstrates the ability to control ion-induced damage independently from the implant dose by elevating the temperature of a sample to $600^{\circ} \mathrm{C}$ during the implant in order to dynamically anneal the $\mathrm{SiC}$ and potentially reduce the damage relative to an implant performed at room temperature. The RBS data show a significant reduction in residual damage (from the surface to $1 / 2 R_{p}$ ) for the hot implant. The optical micrographs indicate that implanting hot also allows a substantial reduction in critical $\mathrm{H}$ dose needed for cleaving the thin $\mathrm{SiC}$ film, resulting with further decrease in damage.

Channeling the $\mathrm{H}^{+}$implant dramatically enhances the process of exfoliation. Measurements of exfoliated area from optical images indicate more robust exfoliation with lower dose relative to random implantation. The SIMS results suggest less out-diffusion of hydrogen during anneal. but increased diffusion into the bulk (below $R_{p}$ ) in the channel-implanted sample. This in turn suggests unique damage morphology at $R_{p}$ which is not entirely understood.

It appears possible for damage in $\mathrm{SiC}$ to reach a concentration great enough to disrupt the formation of a continuous network of cracks. This conclusion is supported when damage is controlled independently of hydrogen concentration, either by elevating the temperature of the $\mathrm{SiC}$ during implant, or by channeling the hydrogen, or, quite possibly both. Each of these methods allows a reduction in critical $\mathrm{H}^{+}$fluence required to affect separation of a thin film and, therefore, may provide high-quality SiCOI material.

\section{REFERENCES}

I. N. Bruel, Electron. Lett. 37, p. 1201 (1995).

2. L. Di Cioccio, Y. Le Tiec, C. Jaussaud, E. Hugonnard-Bruyere, and M. Bruel, Mat. Sci. Forum 264-268, p. 765 (1998).

3. M. K. Weldon, V. E. Marsico, Y. J. Chabal, A. Agarwal, D. J. Eaglesham, J. Sapjeta, W. L. Brown, D. C. Jacobson, Y. Caudano, S. B. Christman, and E. E. Chaban, J. Vac. Sci. Technol. B 15, p. 1065 (1997).

4. W. K. Chu, R. H. Kastle, R. F. Lever, S. F. Mader, and B. J. Masters, Phys. Rev. B I6, p.3851 (1977).

5. C. C. Griffioen, J. H. Evans, P. C. D. Jong, and A. van Veen, Nucl. Instrum. Methods Phys. Res. B27, p. 417 (1987).

6. T. Dalibor, C. Peppermuller, G. Pensi, S. Sridhara, R. P. Devaty, W. J. Choyke, A. Itoh, T. Kimoto, and H. Matsunami, Inst. Phys. Conf. Ser. 142, p. 517 (1996).

7. R. B. Gregory, T. A. Wetteroth, S. R. Wilson, O. W. Holland, and D. K. Thomas, to be published. 